\title{
Median lethal needle caliber in two models of experimental sepsis ${ }^{1}$
}

\author{
Armando José d'AcamporaI, Giovani de Figueiredo Locks ${ }^{\text {II }}$
}

${ }^{\mathrm{I}} \mathrm{PhD}$, Associate Professor, Department of Surgery, Federal University of Santa Catarina (UFSC), Florianopolis-SC, Brazil. Conception, design, intellectual and scientific content of the study, critical revision, final approval of manuscript.

"Master, Division of Anesthesia, Department of Surgery, UFSC, Florianopolis-SC, Brazil. Technical procedures, acquisition and interpretation of data, statistical analysis, manuscript writing.

\section{ABSTRACT}

PURPOSE: To estimate the median lethal needle caliber (LC50) of a new experimental sepsis model and compare it to the LC50 of the cecal ligation and puncture (CLP) sepsis model.

METHODS: Male albino Wistar rats were studied $(n=22)$. Animals were allocated into two study groups. In Group I, experimental sepsis was induced by cecal ligation and puncture. In Group II, experimental sepsis was induced by ascending colon ligation and cecal puncture. Up-and-down method was used to determinate the LC50.

RESULTS: LC50 in Group I was 19 Gauge (Confidence Interval 17 to 22 Gauge). Determination of LC50 was not possible in Group II due to the death of all animals.

CONCLUSION: LC50 in cecal ligation and puncture is 19 Gauge. The lethality of the new model tested in this trial is very high.

Key words: Sepsis. Disease Models, Animal. Rats. 


\section{Introduction}

Sepsis is a severe clinical syndrome characterized as a systemic inflammatory response to infection. Septic shock and multiple organ dysfunction syndrome are possible consequences ${ }^{1}$. Mortality rate due to sepsis is high and varies from 25 to $80 \%{ }^{2,3}$.

Sepsis is the consequence of a complex and multifactorial disarrangement of the host response to infection so the mechanism prepared to defeat the infection becomes the cause of severe tissue injury and dysfunction ${ }^{4}$. Pathophysiology of sepsis is still not completely understood. The most accepted theory is that sepsis is caused by hyperstimulation of the immune system ${ }^{5,6}$. An very complex treatment strategy is crucial to increase the chance of survival for septic patients ${ }^{7}$. Most recommendations, however, are not directed towards sepsis itself, but to secondary target-organs. Efficient and cost-effective new treatments for the handling of sepsis are required. These measures, however, must be developed and tested in animal models before they may be used in critically ill patients ${ }^{8}$.

Experimental models of sepsis have been proposed by many authors due to the extreme variability and the difficulties in setting the stage of human sepsis. The aim of these models is to achieve reproducible studies about pathophysiology and the impact of new therapies ${ }^{9-12}$. Experimental models should replicate the rhythm and severity of human sepsis in the Intensive Care Unit; replicate hemodynamic and immunological stages; replicate histological features of target organs, and show variability between subjects ${ }^{13}$.

Three general models are usually employed to produce experimental sepsis ${ }^{14}$ :

a) Endotoxin injection;

b) Intravascular or intraperitoneal infusion of live bacteria;

c) Induction of fecal peritonitis.

The most utilized model in pre-clinical studies is cecal ligation and puncture because it reflects the complexity of human sepsis ${ }^{15}$. This model satisfies many criteria essential for an experimental model. It contains tissue injury, a necrotic tissue source, and a focal infection source that eventually promotes bacterial translocation, activation of the inflammatory response and septic shock ${ }^{16}$. Advantages of this model include its technical simplicity, polymicrobial origin after a focal infection, re-creation of human sepsis progression, prolonged and lower release of cytokines. Unfortunately, experimental models of sepsis do not perfectly represent the disease or its evolution in human beings ${ }^{11}$. Disadvantages of this method have been described as difficulty in standardization between laboratories; variable factors such as age, genre, and breed; technical discrepancies; and abscess formation ${ }^{15}$.

Mortality in the cecal ligation and puncture model is influenced by needle caliber ${ }^{17}$, number of punctures ${ }^{18}$ and cecal ligation extension ${ }^{19}$. These factors are not always described in procedural details, although they are major determinants of variability in outcome.

A modification of the cecal ligation and puncture model was reported. It was used in other studies in our laboratory ${ }^{20-22}$. In this model, double perforation of the cecum occurs after the ascending colon is ligated.

The aim of this study was to estimate the median lethal needle caliber (LC50, lethal needle caliber in 50\% of cases) of the new model and compare it to the LC50 of the traditional cecal ligation and puncture.

\section{Methods}

After approval by the local Ethical Committee of Animal Use (PP00729/2011), twenty two male albino Wistar rats, weighing between 300 and 450 grams, originating from the Central Animal Colony, Federal University of Santa Catarina, were used. In Group I, fifteen animals were tested. In Group II, seven animals were tested. Animals were kept in individual cages of $60 \times 40 \times 16$ centimeters for a period of 12 days to adapt to the laboratory environment. Animals were maintained under controlled light conditions (12 hours cycles), at controlled temperature $\left(20^{\circ} \mathrm{C}\right)$, and receiving proper food with ad libitum access to water.

\section{Procedures}

All animals were anesthetized with $20 \mathrm{mg}$ of intramuscular Tiletamine + Zolazepam $\left(\right.$ Zoletil $\left.{ }^{\circledR}\right)$. Repeated doses were used if necessary. It was considered anesthetized when there was loss of toe pinch response. Animals were immobilized in dorsal decubitus and anterior abdominal wall was shaved and disinfected with iodopovidone. A midline laparotomy was performed. The cecum was identified and exposed in a non-traumatically manner. Animals were randomly distributed into two study groups. In animals allocated to Group I, the cecum was ligated with 2-0 silk at half the distance between the distal pole and the base of the cecum. In animals allocated to Group II, the ascending colon was ligated with 2-0 silk one centimeter above the ileocecal valve. In both groups, the cecum was punctured twice (Figure 1). The cecum was then gently compressed to extrude a small amount of cecal content 
and the bowel was replaced in the peritoneal cavity. Abdomen was closed in two layers using 3-0 nylon running sutures. After surgery, fluid resuscitation was administered $(5 \mathrm{ml} / 100 \mathrm{~g}$ of $0.9 \%$ sodium chloride subcutaneously) and animals were returned to cage and observed throughout a period of seven days.

\section{Statistical analysis}

The up-and-down method was used to estimate the median lethal needle caliber ${ }^{23}$. This method was proposed by Massey and Dixon, and it was chosen because it requires fewer individuals to determine the Median Lethal Dose (LD50) than traditional methods in pharmacological studies ${ }^{24,25}$. It method consists of a series of sequential essays. The initial caliber used to puncture the cecum in both groups was $22 \mathrm{G}$, which is the gauge caliber reported to be the LC50 in traditional cecal ligation and puncture $^{26}$. If the first specimen survived for a week, the second specimen was tested with a larger needle. If the specimen died in the observation period, the needle used in the next animal was thinner. If an animal was moribund in the observation period, it was submitted to euthanasia through anesthesia overdose and outcome was recorded as death, for ethical reasons. Needle caliber was increased or decreased preferentially according to the even degrees of the Standard Wire Gauge scale.
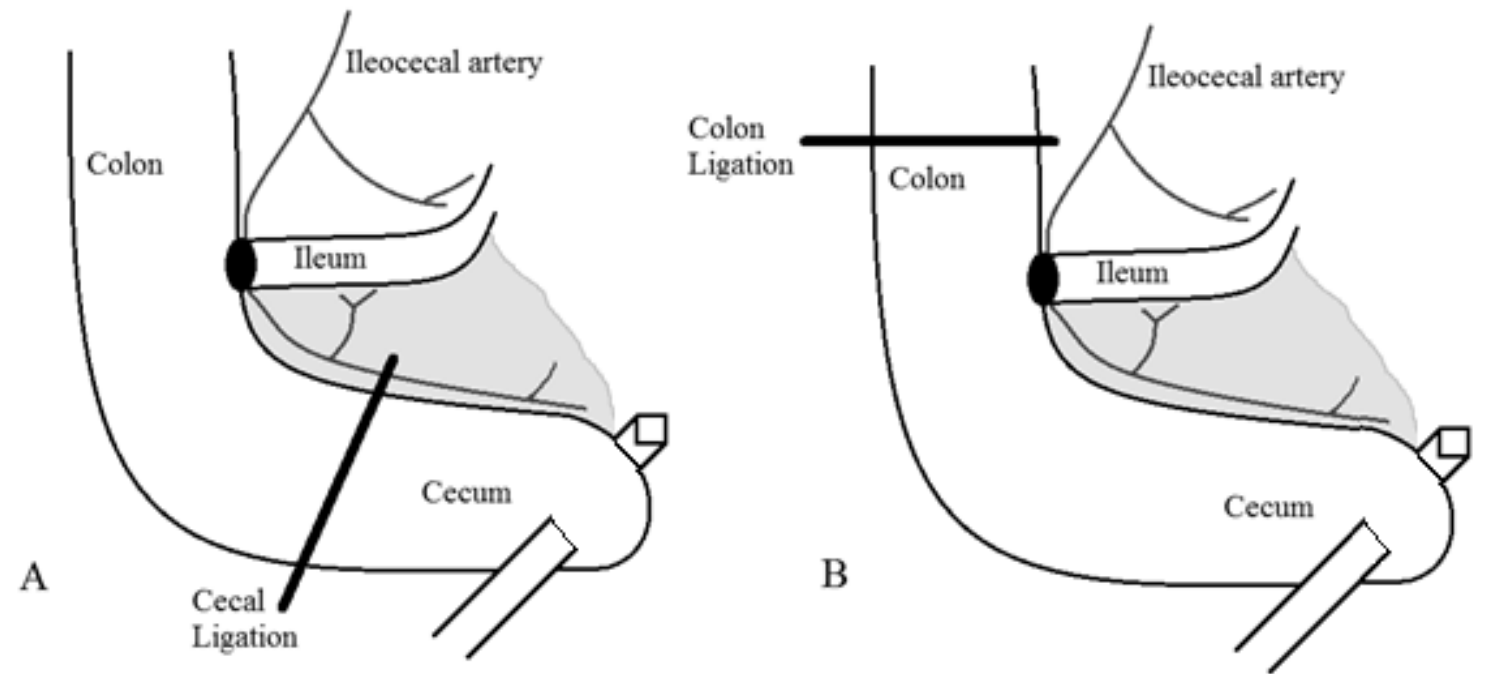

FIGURE 1 - Diagram of both models of experimental sepsis. In the traditional model, cecal ligation was performed (A). In the modified model, ascending colon ligation was performed (B). In both models, the cecum was punctured.

Tests were interrupted if there were five reversions in six consecutive animals; or if there were three consecutive animals who survived or died after testing the superior or inferior limit of needles ( $14 \mathrm{G}$ and 29G respectively); or a maximal 15 animals in each group was accepted. Data were tested to normal distribution using the Shapiro-Wilk test. SPSS v 17.0 was used to perform statistical analysis.

\section{Results}

Needle calibers used to puncture the cecum in both groups are shown in Figure 2. In Group I, LC50 was estimated to be 19G (Confidence Interval 5\% 17 to 22). In Group II, estimation of LC50 was not possible. The test was interrupted due to death of three consecutive animals whose cecum was punctured with the thinnest available needle (29G). 


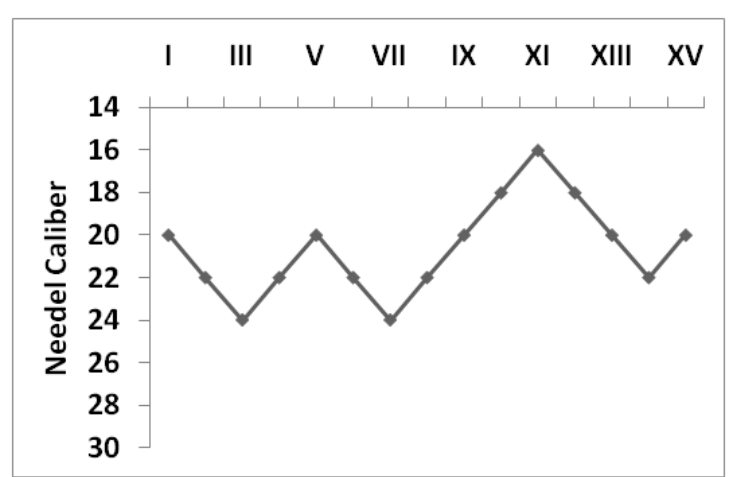

Group I

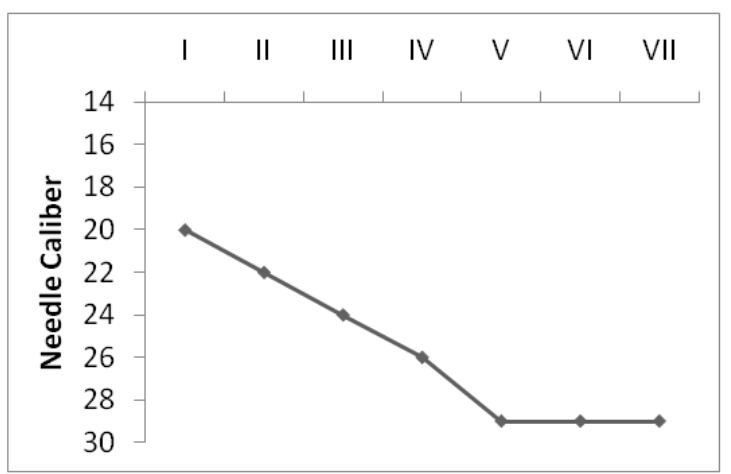

Group II

FIGURE 2 - Needle calibers used to puncture the cecum in two models of experimental sepsis. In Group I, the cecum was ligated. In Group II, the ascending colon was ligated.

\section{Discussion}

Experimental models for the study of sepsis have been proposed since the end of the nineteenth century. At that time, it was believed that bacteria causing peritonitis migrated from the abdomen into systemic circulation by the thoracic duct. In 1898, Noetzel injected Streptococci originating form a sick cow in the peritoneal cavity of rabbits and guinea pigs. The mortality rate of animals with thoracic duct ligation was similar to the control group, but he showed that abdominal toilet increased survival rate. He also detected live bacteria in blood ten minutes after peritoneal injection ${ }^{27}$.

In 1922, Constain also studied the effect of thoracic duct ligation on the peritoneal sepsis evolution in dogs. He ligated the appendix and mesoappendix with chromic catgut and returned it to the abdomen. Necropsy showed the appendix had become gangrenous, and before sufficient walling off could take place, had ruptured into the peritoneal cavity. There was a diffuse septic peritonitis with abundant bloody exudate.

Despite reports of experimental models of sepsis including the puncture of the ligated cecum in the twenties ${ }^{28}$, models of injection of intraperitoneal bacteria and cecal ischemia were the most popular until 1980, when Wichterman standardized the cecal ligation and puncture method ${ }^{9}$. The advantage of puncturing the cecum is to create a more predictable onset than waiting for spontaneous rupture of the residual cecum ${ }^{14}$.

Appendicitis was a cause of great concern before the development of the surgical treatment of peritonitis. Mortality consequential to appendicitis at the end of the nineteenth century was almost $100 \%{ }^{29}$. Nowadays death after appendicitis occurs in 0.07 to 2.4 per thousand surgeries due to the advance of surgeryanesthesia-asepsis ${ }^{30}$.
Cecal ligation and puncture is a model of an inflammatory acute abdomen (caused by appendicitis or diverticulitis). In the new model, there is simulation of an obstructive acute abdomen complicated by intestinal perforation. Mortality in this scenario is significantly higher, even today. Recent reports have demonstrated a mortality rate of 5.9 and $6.9 \%$, despite endoscopic-surgical or surgical treatment respectively ${ }^{31}$.

It is reasonable to assume that intestinal lumen obstruction is responsible for the death of animals allocated to Group II. Pathophysiology of intestinal obstruction is well known. Air and liquid swallowed accumulate onto the obstruction, predisposing it to bacterial multiplication. Gas production is increased, which worsens the case and predisposes to systemic complications by bacterial translocation. If the process is not resolved, there is loss of absorptive capacity of the bowels and fluid shift to intestinal lumen. Such combination leads to electrolytic disturbances and state of shock. There is also loss of blood supply favoring necrosis and perforation ${ }^{32}$. Since 1968, Clowes argued in favor of digestive tract permeability maintenance as essential to the development of sepsis models in the $\operatorname{dog}^{33}$.

In rats, Wichterman found $90 \%$ lethality when an $18 \mathrm{G}$ needle was used to perform a double puncture of the cecum and $77 \%$ when a $22 \mathrm{G}$ needle was used. He also reported no mortality if the specimen survived until the fifth post-operative day ${ }^{9}$. Another study reported a 7-day mortality of $50 \%$ when an $18 \mathrm{G}$ needle was used $^{34}$. There is also variation in mice. Reports of LC50 in mice vary from 21 to $18 \mathrm{G}^{26,35}$. Cecal ligation and puncture may be considered a reproducible method between laboratories despite this variation. ${ }^{15}$

Animal models that lead to significant mortality within the first six to 12 hours may not describe an outcome that is relevant to human sepsis ${ }^{36}$. There must be time enough before death to 
allow sepsis features to be studied. In addition, it is expected a reasonable survival rate. Injuries that are too severe may prevent the appearance of sepsis signs or hinder an efficient therapeutic measure to increase survival rate of milder injuries. The lethality of the new model tested in this trial is very high.

Future studies will define the role of the model "Intestinal Obstruction and Perforation" in the research about physiopathology and treatment of acute sepsis and intestinal obstruction.

\section{Conclusions}

Median lethal needle caliber in cecal ligation and puncture is 19 Gauge. The lethality of the new model tested in this trial is very high and its median lethal needle caliber could not be determined.

\section{References}

1. Bone RC, Balk R A, Cerra F B, Dellinger RP, Fein AM, Knaus WA, Schein RM, Sibbald WJ. Definitions for sepsis and organ failure and guidelines for the use of innovative therapies in sepsis. The ACCP/SCCM Consensus Conference Committee. American College of Chest Physicians/Society of Critical Care Medicine. Chest. 1992;101:1644-55.

2. Angus DC, Linde-Zwirble WT, Lidicker J, Clermont G, Carcillo J, Pinsky, MR. Epidemiology of severe sepsis in the United States: analysis of incidence, outcome, and associated costs of care. Crit Care Med. 2001;29:1303-10.

3. Angus DC, Wax RS. Epidemiology of sepsis: an update. Crit Care Med. 2001;29:S109-16.

4. Hotchkiss R S, Karl IE. The pathophysiology and treatment of sepsis. N Engl J Med. 2003;348:138-50.

5. Treacher DF, Brown KA. The basic science of sepsis. Surgery. 2009;27:465-9.

6. Yang H, Ochani M, Li J, Qiang X, Tanovic M, Harris HE, Susarla SM, Ulloa L, Wang H, DiRaimo R, Czura CJ, Roth J, Warren HS, Fink MP, Fenton MJ, Andersson, U, Tracey KJ. Reversing established sepsis with antagonists of endogenous high-mobility group box 1. Proc Natl Acad Sci USA. 2004;101:296-301.

7. Dellinger RP, Levy MM, Carlet JM, Bion J, Parker MM, Jaeschke R, Reinhart K, Angus DC, Brun-Buisson C, Beale R, Calandra T, Dhainaut JF, Gerlach H, Harvey M, Marini JJ, Marshall J, Ranieri M, Ramsay G, Sevransky J, Thompson BT, Townsend S, Vender JS, Zimmerman JL, Vincent JL. Surviving Sepsis Campaign: international guidelines for management of severe sepsis and septic shock: 2008. Intensive Care Med. 2008;34:17-60.

8. d'Acampora AJ, Rossi LF, Ely JB, de Vasconcellos ZA. Is animal experimentation fundamental? Acta Cir Bras. 2009;24:423-5.

9. Wichterman KA, Baue AE, Chaudry IH. Sepsis and septic shock--a review of laboratory models and a proposal. J Surg Res. 1980;29:189-201.

10. Fink MP, Heard SO. Laboratory models of sepsis and septic shock. J Surg Res. 1990;49:186-96.

11. Deitch A. Animal models of sepsis and shock: a review and lessons learned. Shock. 1998;9:1-11.

12. Buras JA, Holzmann B, Sitkovsky M. Animal models of sepsis: setting the stage. Nat Rev Drug Discov. 2005;4:854-65.

13. Doi K, Leelahavanichkul A, Yuen PS, Star RA. Animal models of sepsis and sepsis induced kidney injury. J Clin Invest. 2009;119:2868-78.

14. Garrido AG, Figueiredo LFP, Silva MR. Experimental models of sepsis and septic shock: an overview. Acta Cir Bras. 2004;19:82-8.

15. Dejager L, Pinheiro I, Dejonckheere E, Libert C. Cecal ligation and puncture: the gold standard model for polymicrobial sepsis? Trends Microbiol. 2011;19:198-208.

16. Hubbard WJ, Choudhry M, Schwacha MG, Kerby JD, Rue LW, Bland KI, Chaudry IH. Cecal ligation and puncture. Shock. 2005;24 Suppl 1:52-7.

17. Ebong S, Call D, Nemzek J, Bolgos G, Newcomb D, Remick D. Immunopathologic alterations in murine models of sepsis of increasing severity. Infect Immun. 1999;67:6603-10.

18. Baker CC, Chaudry IH, Gaines HO, Baue AE. Evaluation of factors affecting mortality rate after sepsis in a murine cecal ligation and puncture model. Surgery. 1983;94:331-5.

19. Singleton KD, Wischmeyer PE. Distance of cecum ligated influences mortality, tumor necrosis factor-alpha and interleukin-6 expression following cecal ligation and puncture in the rat. Eur Surg Res. 2003;35:486-91.

20. Bernhardt J A, d'Acampora AJ, Tramonte R, Serafim JD. Effect of post-natal castration on sepsis mortality in rats. Acta Cir Bras. 2007;22:22-9.

21. d'Acampora AJ, Bernhardt JA, Serafim JDM, Farias DC, Tramonte R. Efeitos da castração pós-natal sobre o tecido pulmonar após sepse experimental de origem abdominal em ratos. Acta Cir Bras. 2004; 19:115-9.

22. Kestering DM, d'Acampora AJ, Farias DC, Brum SP, Ely JB. Rats resistance to fecal peritonitis when subjected to total splenectomy and auto-implant of the spleen in the retroperitoneum. Acta Cir Bras. 2005;20:473-7.

23. Dixon WJ, Massey FJ. The "up-and-down" method. Introduction to statistical analysis. New York: McGraw-Hill; 1957.

24. Lipnick RL, Cotruvo JA, Hill RN, Bruce RD, Stitzel KA, Walker AP, Chu I, Goddard M, Segal L, Springer JA, Myers RC. Comparison of the up-and-down, conventional LD50, and fixed-dose acute toxicity procedures. Food Chem Toxicol. 1995;33:223-31.

25. Lichtman AH. The up-and-down method substantially reduces the number of animals required to determine antinociceptive ED50 values. J Pharmacol Toxicol Methods. 1998;40:81-5.

26. Walley KR, Lukacs NW, Standiford TJ, Strieter RM, Kunkel SL. Balance of inflammatory cytokines related to severity and mortality of murine sepsis. Infect Immun. 1996;64:4733-8.

27. Noetzel W. Ueber peritoneale resorption und infection. Arch Klin Chir. 1898;57:311-21.

28. Steinberg B. Experimental production of general peritonitis: with an anatomic study. Am J Pathol. 1926;2:415-20.5.

29. Hau T. The history of peritonitis. Acta Chir Austriaca. 2000;32:157-61.

30. Blomqvist PG, Andersson RE, Granath F, Lambe MP, Ekbom AR. Mortality after appendectomy in Sweden, 1987-1996. Ann Surg. 2001;233:455-60

31. Tan CJ, Dasari BV, Gardiner K. Systematic review and meta-analysis of randomized clinical trials of self-expanding metallic stents as a bridge to surgery versus emergency surgery for malignant left-sided large bowel obstruction. Br J Surg. 2012;99:469-76.

32. Kahi CJ, Rex DK. Bowel obstruction and pseudo-obstruction. Gastroenterol Clin North Am. 2003;32:1229-47.

33. Clowes GH Jr, Zuschneid W, Turner M, Blackburn G, Rubin J, Toala P, Green G. Observations on the pathogenesis of the pneumonitis associated with severe infections in other parts of the body. Ann Surg. 1968;167:630-50. 
34. Rittirsch D, Huber-Lang MS, Flierl MA, Ward, PA. Immunodesign of experimental sepsis by cecal ligation and puncture. Nat Protoc. 2009;4:31-6.

35. Maier S, Traeger T, Entleutner M, Westerholt A, Kleist B, Huser N, Holzmann B, Stier A, Pfeffer K, Heidecke CD. Cecal ligation and puncture versus colon ascendens stent peritonitis: two distinct animal models for polymicrobial sepsis. Shock. 2004;21:505-11.

36. Piper RD, Cook DJ, Bone RC, Sibbald WJ. Introducing critical appraisal to studies of animal models investigating novel therapies in sepsis. Crit Care Med. 1996;24:2059-70.

\section{Correspondence:}

Dr. Giovani de Figueiredo Locks

Departamento de Cirurgia-Hospital Universitário

Campus Universitário, sn

88.000-000 Florianopolis - SC Brasil

giovanilocks@gmail.com

Received: Sept 12, 2013

Review: Nov 14, 2013

Accepted: Dec 12, 2013

Conflict of interest: none

Financial source: none

${ }^{1}$ Research performed at Laboratory of Experimental Surgery, Department of Surgery, University Hospital, Federal University of Santa Catarina (HU-UFSC), Florianopolis-SC, Brazil. 